\title{
Pandemia, museu e virtualidade: a experiência museológica no "novo normal" e a ressignificação museal no ambiente virtual
}

Pandemic, museum, and virtuality: museological experience in the "new normal" and the resignification of museum in the virtual environment

https://doi.org/10.1590/1982-02672021v29e54

\author{
ANDRÉ FABRÍCIO SILVA' \\ https: / / orcid.org/0000-0003-4999-1987 \\ Universidade Federal do Estado do Rio de Janeiro / Rio de Janeiro, RJ, Brasil
}

RESUMO: O surgimento do coronavírus causador da covid-19 trouxe novos desafios para os museus, na medida em que o fato de a pandemia ter passado a exigir distanciamento e isolamento social como medidas para a prevenção do contágio, impactou a rotina dos museus e sua relação com o público. Nesse novo cenário, a comunicação virtual se ressignifica dentro das instituições museológicas. Com o uso do meio virtual como única forma de os museus se comunicarem com seu público, uma série de fatores suscitam algumas discussões que permeiam a virtualidade. Nesse sentido, considerando o uso de tecnologias no ambiente web pelos museus, pretendemos analisar de que maneira algumas instituições museológicas ressignificaram suas ações diante da pandemia e como pensar as ações futuras em interface com o meio virtual tornou-se um grande desafio para os museus. Assim, por meio da abordagem de discussões teóricas que envolvem virtualidade, musealização e digitalização do objeto museológico, o artigo propõe uma reflexão acerca dos desafios enfrentados pelos museus no período da pandemia e sobre como repensar os usos da virtualidade por essas instituições no período pós-quarentena.

PALAVRAS-CHAVE: Virtual. Covid-19. Museus. Objeto museológico digital. Público virtual. Comunicação virtual.

\begin{abstract}
1. Doutorando e mestre pelo Programa de Pós-Graduação em Museologia e Patrimônio da Universidade Federal do Estado do Rio de Janeiro (Unirio). Licenciado em História e bacharel em Museologia pela Universidade Federal de Ouro Preto (Ufop). Coordenador do Programa de Educação Patrimonial da Prefeitura Municipal de Mariana/MG. Atua como Museólogo na empresa Conectamus, prestando serviços de pesquisa e levantamento de acervo físico e digital, catalogação de acervo, elaboração de material de pesquisa expográfica e de política de acervos. E-mail: <andrefabricio. sil@gmail.com>.
\end{abstract}


ABSTRACT: With the outbreak of the novel coronavirus (Sars-CoV-2) and the ensuing demand for measures of social distancing and isolation as a means to prevent contagion, museums had to face a number of new challenges that impacted their lives and their relationship with the audience. With the use of virtual media as the only channel for museums to communicate with their public, virtual communication is resignified within museological institutions, raising a number of factors that contribute to the debate on virtuality. Considering the use of technologies in the web environment, this article aims to analyze how some museological institutions resignified their actions in the face of the pandemic and how the virtual environment has become a major challenge for them to think about their future actions. Based on theories of virtuality, musealization, and digitization of museum objects, it proposes a reflection on the challenges faced by museums during the pandemic period, as well as on how to rethink the uses of virtuality in the post-quarantine period.

KEYWORDS: Virtual. Sars-CoV-2. Museums. Digital museum object. Virtual public. Virtual communication. 
Quando adentramos o século XXI com um sentimento marcado por um espírito de renovação e enfrentamento de desafios pelas instituições museológicas, certamente a possibilidade de enfrentar uma grande pandemia não estava prevista. O surgimento do novo coronavírus, nomeado de Sars-CoV-2, trouxe novos desafios para os museus a partir do momento em que a pandemia passou a exigir distanciamento e isolamento social como medidas indispensáveis para a prevenção do contágio, o que impactou a rotina dos museus e sua relação com o público.

Sabemos que as crises pandêmicas mudaram o funcionamento normal da vida das nações, sujeitando suas estruturas às tensões inesperadas e, em certas circunstâncias, levando-as ao colapso. Pandemias mudam o mundo e a história nos mostra que podem provocar grandes transformações na sociedade. A peste negra, que tomou a Eurásia na virada da década de 1341 para 1351, transformou a Europa. Diante da pandemia, a cultura, que antes era marcada pelo cristianismo, obrigou-se a lidar com a inépcia da salvação divina. Destaca-se a filosofia moral do Humanismo, que concebe o indivíduo como elemento central do universo. A Idade Média foi gradualmente "deixada para trás", à medida que o saber científico e uma arte centrada na figura humana - e não mais em Deus - tornaram-se predominantes. Assim, a virada para a Renascença foi a maior transformação como reflexo das mudanças ocasionadas pela pandemia da peste negra. ${ }^{2}$

Já no início do século XX, entre 1918 e 1920, o primeiro vírus a ser transmitido de maneira global, causador da gripe espanhola, provocou uma transformação no espírito da humanidade. A pandemia levou à morte mais de 50 milhões de pessoas de todo o mundo. Concomitantemente a ela, vimos surgir uma espécie de aceleração do tempo, que provocou importantes transformações sociais em todos os setores da sociedade. Foi um tempo de rápido avanço tecnológico e de busca acelerada pela felicidade, além de uma série de quebras de paradigmas. A moda se transformava, explodia o cinema e a rádio, o telefone se popularizava e os sistemas de saúde se ampliavam em meio ao enfrentamento da crise espanhola. ${ }^{3}$

As pandemias contribuem para o aceleramento das tecnologias, promovem proximidades e modificam os valores da sociedade, alterando critérios préestabelecidos e gerando profundas transformações no âmbito social. Vemos agora ocorrer novamente esse fenômeno, que certamente transformará a cultura, a economia, os valores e, principalmente, a relação com as tecnologias. Nesse sentido, os museus foram umas das instituições mais intensamente afetadas pelos impactos da pandemia. Instantaneamente, viram-se obrigados a fechar suas portas, 
4. O termo home office, traduzido literalmente, significa "escritório em casa". Na prática, refere-se a uma estrutura própria que o profissional tem na sua residência para realizar tarefas de trabalho, tal qual em sua empresa. A partir da pandemia e do isolamento obrigatório, ele ganhou variações, principalmente quando do trabalho remoto e especialmente nas instituições museológicas, visto que precisam continuar a funcionar adaptando-se à atual realidade. Isso demanda o cuidado dos acervos dos museus por meio da gestão online, assim como a inclusão de obras digitais no acervo virtual.

5. Bowen (1999).

6. Lévy (2011).

7. Ibid. Deleuze apud Lévy, op. cit.

8. Ibid., p. 7. colocar suas equipes em trabalho em regime de home office 4 e pensar em novas estratégias de comunicação com o público. Nesse novo cenário, devido à imposição de isolamento e distanciamento social, a comunicação virtual tomou um novo significado. Com o uso do meio digital como única maneira de os museus se comunicarem com seus públicos, emerge uma série de fatores que suscitam algumas discussões que permeiam a virtualidade.

Nesse sentido, pretendemos aqui analisar como algumas instituições museológicas, principalmente as brasileiras, ressignificaram suas ações diante da pandemia e como pensar suas ações futuras nesse processo de virtualidade tornou-se um grande desafio para os museus. Além disso, lançamos um olhar que busca compreender como o uso da virtualidade desperta uma série de desafios para os museus, que comumente vemos serem discutidos somente no âmbito de ação dos espaços físicos.

\section{VIRTUAL E REAL: SINCRONICIDADE NO CAMPO MUSEAL}

Em seu artigo "Time for renovations: a survey of museum web sites", em que buscava estabelecer os problemas dos museus na sua presença na web, Jonathan P. Bowen afirmava que "virtual museums interact with virtual visitors, just as real museum interact with real visitors". 5 Tal afirmação traz alguns pontos que nos fazem refletir sobre algumas questões, como: como se estabelecem as ações dos museus no meio virtual? Ou, o que seria um público virtual? Mais do que isso, o que podemos entender como virtual? Ele pode ser considerado oposto do real?

Para Pierre Lévy, o virtual não se opõe ao real. 6 ○ autor entende o virtual como um movimento que existe em potência e não em ato. Sendo assim, ele se opõe ao atual, ou, como define Gilles Deleuze, ao possível, que se caracteriza como um estado que permanece no limbo, esperando a sua existência. ${ }^{7}$ Para o autor, a realização de um possível, que se estabelece no real, não é uma criação, pois a criação implica uma produção inovadora de ideias ou formas. Então, a virtualização é definida como o inverso do atual, da atualização, pois "virtualizar uma entidade qualquer consiste em descobrir uma questão geral à qual ela se relaciona, em fazer mutar a entidade em direção a essa interrogação e em redefinir a atualidade de partida como resposta à uma questão particular". ${ }^{8}$

Podemos compreender em Lévy que a virtualização é um dos principais vetores de criação da realidade. Ela permite que pessoas, coletividades, informações, 
tornem-se "não-presentes", o que viabiliza um processo de desterritorialização. Removido do espaço físico, o virtual não é apenas imaginário, pois produz efeitos sobre os sujeitos. Ao provocar esse processo de desterritorialização, ele permite a saída da "presença", do "agora"; virtualiza os sentidos e transmite, muito mais que imagens, a quase presença. ${ }^{9}$ Dessa forma, podemos compreender a virtualização como um processo de materialização do real.

Quando abordamos o tema da virtualização no âmbito dos museus, levantase o debate sobre os processos de virtualização do objeto museológico e a própria possibilidade de captação do que Walter Benjamin chamou de "aura do objeto". 10 Para Benjamin, a reprodução técnica do objeto de arte acarretaria na perda da autenticidade desse objeto por retirar a aura característica e única de sua existência. " André Malraux, por sua vez, estabelece uma relação dialógica com Walter Benjamin, mas diverge dele quanto à reprodutibilidade do objeto ao pensar o conceito de Museu Imaginário, um museu mental, que pode ser representado como um espaço virtual que transita entre o real e o imaginário. ${ }^{12}$ Ao problematizar a função dos museus ditos "tradicionais", na medida em que estes estabelecem uma relação entre espectador e obra de arte, Malraux destaca a importância da interação entre museus, cultura e sociedade, pensando a própria relação que os sujeitos estabelecem com o objeto artístico dentro dos museus. Centrado na metamorfose do objeto, que se desloca do seu sentido "primitivo" no processo histórico, Malraux acredita que a reprodução do objeto permite que se estabeleça outras relações com ele e ajuda a modificar o diálogo entre a obra e o sujeito. ${ }^{13}$ No Museu Imaginário, a reprodutibilidade do conjunto das obras permite ao sujeito conhecer os objetos dos museus sem necessariamente se deslocar até eles. Assim, a metamorfose representaria a própria vida da obra de arte e suas ressignificações a partir da percepção de cada indivíduo no contato com essa reprodução. ${ }^{14}$

As acepções aqui destacadas permitem entender a virtualização do objeto, diante do advento das novas tecnologias, como um processo que amplia o campo de atuação dos museus, a partir do momento em que eles se inserem nesse processo de disseminação de informações sobre os objetos por eles adquiridos para além do seu espaço físico. Segundo Tereza Scheiner, as novas tecnologias midiáticas favorecem uma captura ampliada do patrimônio, na medida em que "o meio eletrônico apreende e homogeneíza a imensa pluralidade de objetos patrimonializados e os transforma, por sua vez, em novos ícones patrimoniais - os documentos virtuais". ${ }^{15}$ As possibilidades da realidade virtual, da realidade ampliada, da digitalização de objetos e o desenvolvimento dos objetos culturais digitais, representam uma reconfiguração do objeto material, que assume novas formas e funções, potencialidades e significados, no meio virtual. Esse fenômeno
9. Ibid., p. 4 .

10. Benjamin (1987a).

11. Walter Benjamin estabelece sua análise em um contexto em que o processo de reprodução passou a ser realizado em massa pelas indústrias ou por meio de uma perspectiva de câmera, de forma rápida $\mathrm{e}$ idêntica à obra original. Isso permitiu que o espectador tivesse acesso a uma infinidade de reproduções artísticas que, segundo Benjamin, provocam a perda de autenticidade desses objetos. Para o autor, a reprodução técnica desvaloriza o aqui e agora e despreza as marcas físicas de sua história e a tradição cultural na herança dessas obras. Perde-se a aura da arte, que, para Benjamin, seria a figura singular do objeto, composta de elementos espaciais e temporais (BENJAMIN, 1987b). Nesse sentido, as obras deixam de ser únicas e exclusivas e se tornam bens comuns e idênticos.

12. O conceito de museu imaginário elaborado por Malraux caracteriza-se por dois elementos distintos: em um primeiro momento, ele aborda o Museu Imaginário como um museu de imagens que abrange a totalidade do que as pessoas conhecem sobre a arte, pois, como não foram a um museu, têm contato com a arte somente por meio da reprodução. Para Malraux, as técnicas de reprodução tinham um caráter positivo, pois permitia aos indivíduos conhecerem produções artísticas de civilizações passadas, que, distantes no espaço e no tempo, tornam-se atópicas e atemporais com a reprodução, de modo que podem ser apreciadas em diferentes espaços e momentos históricos. Além dessa ideia, a que mais se destaca no 
pensamento de Malraux está relacionada ao museu como "lugar mental", um espaço imaginário e sem fronteira que reside nos sujeitos. Aqui, o museu não se estrutura por meio das reproduções, mas é concebido de maneira mental (MALRAUX, 2006).

13. Mario Chagas faz uma importante colocação para compreendermos como o processo de metamorfose apresentado por Malraux se insere em uma lógica de redimensionamento dos processos de acesso aos objetos dos museus. Segundo Mário Chagas, "o Museu Imaginário contribuiu para o reposicionamento da questão do público no museu. O advento da imprensa de arte, bem como das reproduções técnicas cada vez mais bem-feitas, permitiu que estudantes, artistas, pesquisadores e demais públicos pudessem acessar informações sobre obras e conjuntos de obras de uma maneira inteiramente nova. [...] A grande circulação de imagens propiciou novas negociações de sentidos e permitiu também que os públicos visitantes de museus concretos e institucionalizados tratassem as obras com alguma familiaridade. [...] Em muitos casos, a reprodução técnica da obra estimula a cerimônia de 'beija-mão' do original e, em outros, a própria reprodução é investida de potência aurática. De outro modo: a condição aurática de uma obra de arte, diferentemente do que se poderia imaginar, não é destruída com a sua reprodução; ela é apenas redimensionada" (CHAGAS, 2003, p. 245).

14. Malraux, op. cit.

15. Scheiner (2004, p. 230).

16. Walsh (2000).

17. Segundo o dicionário Britannica, o desenvolvimento da World Wide Web da virtualização é ainda recente e, devido ao seu efeito sobre o campo cultural, tem gerado uma série de discussões.

\section{USOS DA VIRTUALIDADE: A COMUNICAÇÃO VIRTUAL COM O PÚBLICO DE MUSEUS}

As tecnologias se transformam e, na mesma medida, mudam a forma como vemos e interagimos com a realidade. Diante da relação que estabelecemos com o mundo a partir do olhar, Peter Walsh afirma que todas as tecnologias estão diretamente ligadas às capacidades cognitivas e naturais dos seres humanos. ${ }^{16}$ Pinturas rupestres, o alfabeto escrito, litografia, fotografias, imagens em movimentos, filmes, televisão, radar, computadores, gravações de som e rádio, a World Wide Web, ${ }^{17}$ são algumas tecnologias que transformaram a nossa percepção sobre a realidade. ${ }^{18}$ Nesse processo de mudanças tecnológicas, Walsh entende a World Wide Web como uma espécie de apoteose das tecnologias visuais, na medida em que une no mesmo espaço mídias, filmes, gravações de sons, livros, objetos, que, por meio da virtualidade, transmitem seus efeitos correspondentes e incidem diretamente na percepção dos sujeitos. Os museus como elementos transformadores ganham grande destaque nesse processo, a partir do momento em que a internet permitiu viagens "extracorpóreas" nos espaços museais, onde a vivacidade dessas experiências virtuais promove um profundo efeito sobre a nossa consciência social e política. ${ }^{19}$

A chegada da web facilitou o desenvolvimento de hipermídias com informações de museus que atraíram um número elevado de interação de usuários de todas as partes do mundo com os espaços museais. A possibilidade de uma ampliação das ações dos museus no meio virtual traz consigo reflexões que envolvem os usos dos museus no espaço virtual, assim como a sua relação com o público virtual. ${ }^{20}$ Fabio Paternò e Cristiano Mancini destacam que, assim como os espaços museológicos têm um público específico e algumas ações dos museus devem ser pensadas segundo o perfil desse público, da mesma maneira deve-se proceder ao interagir com o público virtual. ${ }^{21}$ Distintas são as interações dos usuários com os museus, pois tais usuários são variados e executam tarefas em vários contextos. Por isso, os autores afirmam que os meios virtuais dos museus de interação com o público devem ter interfaces capazes de se adaptarem aos diferentes perfis de usuário, a fim de estabelecerem, de maneira efetiva, os objetivos dos museus. ${ }^{22}$

É interessante pensar esse aspecto do objetivo dos museus, pois sua essência ancora-se nos usos dos objetos da cultura que se estruturam como elemento 
de comunicação em determinada realidade. Ivo Maroević realiza profunda análise sobre os objetos dos museus, que servem como ferramentas essenciais nos processos de comunicação. ${ }^{23}$ Conforme aponta em seus estudos, a característica de um objeto de museu reside em sua musealidade, elemento que permite que o objeto, ao ser separado do seu ambiente real e colocado em um espaço museal, torne-se um documento daquela realidade, ou seja, uma museália, um objeto de museu. Segundo Maroević, nem todas as camadas da musealidade podem ser descobertas nos processos de comunicação entre objeto e usuário que ocorrem no ambiente museal. Assim, a museália, com a sua materialidade, mantém-se como um documento do tempo, registrando seu tempo e sua existência, penetrando na sociedade na forma de informações culturais, científicas e poliestratificadas. $\bigcirc$ seu conteúdo, a sua musealidade, é formulado em mensagens e atua no espaço, de modo que o museu é a instituição central nesse processo de comunicação.

Assim, os museus, com suas coleções e suas atividades de coletar e selecionar objetos, de estudar e descobrir suas qualidades ocultas e de exibir ou disseminar suas mensagens por meio de sistemas de documentação-informação, têm infinitas possibilidades de estabelecer um processo de comunicação com os objetos. Nesse sentido, o grande desafio é transpor essa comunicação da realidade dos museus para o espaço virtual. Isso se refere ao próprio processo de interação dos usuários com os objetos dos museus virtualizados. Essas interações podem possibilitar o acesso às diversas camadas da musealidade destacadas por Ivo Maroević.

Essa parece ter sido a preocupação de alguns museus, quando voltamos nosso olhar para o contexto de explosão do uso da internet nos anos 1990, quando um número significativo de museus estabeleceu a sua presença na web. ${ }^{24}$ Como observado por Bowen, os museus, por meio de sua coleção de objetos e informações, passaram a estruturar - para fins educacionais, de pesquisa e de entretenimento - diversas ferramentas online como espaço de interação com o público. $\bigcirc$ estudo de Bowen oferece importante panorama do contexto, destacando alguns museus como o The Museum of Science, em Boston (EUA), que originalmente produziu um site em 1995 e incluiu o uso de novas tecnologias como parte de sua missão. Ressalta, também, o projeto Australian Museums On-Line, de 1999, que se configurou como um importante portal de pesquisa, na medida em que chegou a disponibilizar mais de 350 mil acervos registrados pelos museus australianos. Outro grande projeto foi o desenvolvido pela Technisches Museum Wien em 1999 na Áustria. Focado no pensamento futurista, debateu o papel do visitante na interação com o museu quando interage com os objetos museológicos em um ambiente imersivo criado por meio de técnicas de inteligência artificial. foi iniciado em 1989 por Tim Berners-Lee e seus colegas da Organização Europeia para a Pesquisa Nuclear (CERN), uma organização científica internacional com sede em Genebra, Suíça. Eles criaram um protocolo, o Hyper Text Transfer Protocol (HTTP), que padronizou a comunicação entre servidores e clientes Seu navegador baseado em texto foi disponibilizado para lançamento geral em janeiro de 1992. A web é o principal serviço de recuperação de informações da Internet (rede mundial de computadores) e opera dentro dos padrões básicos da Internet, no formato cliente-servidor, em que os servidores são programas de computadores que armazenam e transmitem documentos para outros computadores na rede quando solicitados. Já clientes são programas que solicitam documentos de um servidor conforme o usuário os solicita.

18. Walsh, op. cit.

19. Ibid.

20. É importante destacar qual o aspecto virtual do museu que abordamos neste artigo. Conforme destaca Tereza Scheiner, existe uma duplicidade de interpretação quanto ao que seja museu virtual e os chamados cibermuseus. Tereza Scheiner e Bernard Deloche (2001) designam o Museu Virtual como o espaço dos registros produzidos diretamente em meio virtual, como os diferentes produtos de hipermídia criados em variados suportes - CD-ROMs, DVDs, videotextos, games e computadores. $\mathrm{O}$ museu virtual é um espaço virtual de mediação e de relação do patrimônio com os públicos virtuais. É um museu paralelo e complementar, uma criação exclusiva do ambiente virtual, 
que ganha corpo e forma na tela do computador, que destaca a comunicação como forma de apresentar determinado patrimônio, estabelecendo suas ações museológicas num espaço virtual. Nos cibermuseus, o conceito de "virtual" caracteriza efetivamente a metamorfose aplicada à imagem e ao texto, dado que matérias compõem a realidade comunicacional da maioria dos museus (SCHEINER, 2004). Nesse espaço, todos os recursos de documentação, interpretação e conservação são transformados em representações digitais e virtuais dos acervos preservados. Dessa forma, os cibermuseus se definem como reproduções online do acervo ou parte do acervo de determinado museu. Nessa lógica, buscamos tratar neste artigo de museus físicos que buscam intermediar suas exposições no campo virtual, isto é, sobre como os museus buscam comunicar seus acervos museológicos físicos no âmbito virtual.

21. Paternò e Mancini (2000).

22. Ibid.

23. Maroević (1986).

24. Bowen, op. cit.

25. Paternò e Mancini, op. cit.

26. Ibid.
O público virtual é o elo de destaque que interliga o objeto dos museus e as ações no ambiente virtual. Bowen entende que, para o museu realizar em sua amplitude os complexos procedimentos de comunicação dos objetos no ambiente virtual, é necessário entender não somente o valor tridimensional do objeto, mas também sua forma virtual, ou seja, deve-se pensar de que maneira as exposições, seja de longa duração seja temporária, podem estabelecer uma experiência ampliada com os objetos dos museus. Por esse ângulo, o autor afirma que os museus terão que, cada vez mais, fornecer material multimídia para promover uma experiência virtual interativa semelhante às experimentadas nos espaços físicos, e sugere que no futuro parte das exposições sejam elaboradas de maneira que possam ser acessadas tanto no plano físico quanto no virtual, mediante uma experiência de curadoria que trabal he conjuntamente os objetos nesses dois espaços.

O perfil do público de museus se relaciona de maneira direta com a forma como uma exposição é projetada. Quando pensamos o aspecto da curadoria voltada para o público virtual, é importante levar em consideração e entender como esse público visita os museus, a fim de construir uma exposição adaptativa para sites de museus que projetam técnicas de interfaces adaptáveis e adaptativas a esse público. No final dos anos 1990, Paternò e Mancini perceberam a necessidade de os museus produzirem interfaces digitais capazes de se adaptarem aos diferentes requisitos dos usuários virtuais, de maneira a facilitar os objetivos das instituições museológicas. ${ }^{25}$ Segundo os autores, diversos são os motivos da interação do usuário com sites de museus e distintas são as tarefas realizadas. $\bigcirc$ advento da web permitiu o desenvolvimento de hipermídias com informações relacionadas aos museus que podem ser acessadas por uma variedade de usuários de diversas partes do mundo. Tomam como exemplo os trabalhos desenvolvidos pelo Marble Museum em 1997, que criou sua plataforma de navegação no intuito de permitir que o usuário selecionasse um perfil de visita que desejasse realizar, por exemplo: um especialista, um estudante de arte ou um turista. O objetivo era elaborar um sistema adaptável ao usuário possibilitando que o conteúdo acessado em uma página fosse determinado de acordo com o conhecimento e o objetivo de cada um. ${ }^{26}$

Como visto, os processos de transformações provocados nos planos de ação dos museus como reflexo dos avanços tecnológicos digitais, decorreram de uma série de esforços de adaptações das ações dos museus no espaço web. Mesmo que haja interesses no público, nos procedimentos de navegações e na interação dos usuários com o ambiente virtual dos museus, o ponto central nesse processo ainda é o objeto do museu. Como destacado anteriormente nas reflexões de Maroević, a característica do objeto reside na sua musealidade enquanto documento do real passível de se tornar uma museália, um objeto de museu. 
grande debate que emerge é se esse objeto, quando é previamente digitalizado e disponibilizado no ambiente virtual, perde seu sentido, sua musealidade ou sua museália. Conforme evidenciou-se inicialmente, o processo de virtualização, segundo Lévy, não implica que o objeto digitalizado seja o oposto do real. Para Marina Gowert do Reis, apoiando-se em Bianchini, o virtual, a despeito de não existir fisicamente, é capaz de produzir efeitos e influenciar na realidade física. ${ }^{27}$ Nesse sentido, a autora caracteriza a cibercultura como um espaço em que o virtual se relaciona com o real, na medida em que o processo de virtualização do objeto museal corresponde à virtualização da informação, transmitida no ambiente virtual. ${ }^{28}$ Dessa forma, busca desmistificar a ideia de que o objeto no plano virtual não abrange informações que se ligam ao objeto físico. Conforme destaca a autora, "o patrimônio digitalizado é muito mais uma nova forma de acesso, que proporciona uma experiência diferente da presença dos originais". ${ }^{29}$

Renata Cardozo Padilha caminha na mesma dinâmica ao discutir a ampliação dos usos das ferramentas digitais pelos museus, pois afirma que esses espaços estão sendo impelidos a reformularem suas ações e a buscarem ampliar seus públicos inserindo os objetos museológicos no ambiente web. ${ }^{30} \mathrm{~A}$ autora aborda um importante conceito que envolve as reflexões aqui propostas, referente ao uso dos objetos musealizados no ambiente virtual. $\bigcirc$ objeto, ao passar por um processo de musealização, é retirado de sua configuração real para se tornar um bem patrimonial ou adquirir um status de patrimônio. ${ }^{31}$ Assim, musealizar um objeto representa inseri-lo no museu por meio de uma série de procedimentos técnicos, transformando-o em testemunho de uma determinada cultura ou sociedade, o que passa a configurá-lo como um suporte de informação. Quando esse objeto é transportado para o ambiente digital, por meio da digitalização e da reprodutibilidade digital que modificam seu formato e conteúdo, Padilha define-o como um objeto que passou a ter uma dimensão virtual, como um "objeto museológico digital". Para a autora, o "objeto museológico digital" é o objeto que é

reproduzido para o formato digital a partir de um objeto museológico físico ou concebido originalmente nesse meio, salvaguardado em instituições museológicas, [...] passa a receber uma carga valorativa patrimonial, documental e informacional tendo em vista sua nova história, usos e disseminação por meio do ambiente web. ${ }^{32}$

A autora nos chama a atenção para os processos de musealização desses objetos no âmbito virtual. A reprodutibilidade digital do objeto museológico mantém a sua "aura"33 e, devido a essa proximidade, esse suporte digital como objeto informacional deve ser musealizado de igual maneira, levando em consideração
27. Bianchini apud Reis, 2019 , p. 33.

28. Ibid.

29. Ibid., p. 34.

30. Padilha (2018).

31. Cf. Cury (2006).

32. Padilha, op. cit., p. 21.

33. Aqui, a aura é entendida segundo o conceito elaborado por Walter Benjamin (BENJAMIN,1987a). 
34. Ibid.

35. Reis, op. cit., p. 52.

36. Padilha (2018) identifica no Modelo de Referência Conceitual Cidoc-CRM as classes que dialogam com a representação de objetos museológicos digitais na perspectiva da reprodutibilidade técnica e de seus conceitos relacionados. Com o objetivo de contribuir para uma discussão atualizada da documentação museológica, fundamentada no documento internacional do campo da Museologia e dos museus, quanto às mudanças do objeto museológico salvaguardado em instituições museológicas, destaca no Cidoc-CRM as classes que dialoguem com o objeto museológico digital na perspectiva da reprodutibilidade técnica. As classes apresentadas são: E2 Entidade Temporal, E4 Período, E5 Evento, E7 Atividade, E11 Modificação, E12 Produção, E18 Coisa Física, E24 Coisa Física Feita Pelo Homem, E36 Item Visual, E38 Imagem, E39 Ator, E52 Intervalo de Tempo, E53 Lugar, E55 Tipo, E57 Material, E63 Início da Existência, E70 Coisa, E73 Objeto de Informação, E77 Item Persistente, E79 Adição de Parte, E80 Remoção de Parte, E84 Suporte de Informação, E89 Objeto Proposicional e E90 Objeto Simbólico. o seu caráter digital e todos os processos de musealização. O objeto museológico físico, ao ser reproduzido digitalmente, passa a configurar uma nova existência digital no âmbito virtual - e, portanto, institui-se com uma nova vida no tempo a partir da sua reprodutibilidade. ${ }^{34}$

A validação da "aura" desse objeto e o seu reconhecimento pelo público ou por usuários do ambiente web, perpassam o reconhecimento de que o objeto tem uma nova história e novos usos que requerem que ele se enquadre na "forma contemporânea intencional de armazenar, preservar, organizar e difundir bens patrimoniais". ${ }^{35}$ Esse objeto museológico digital torna-se um outro, que se diferencia do seu referencial de origem. A partir da sua identidade própria, deve passar por um processo de musealização em que se pense a sua função informacional no âmbito digital. ${ }^{36}$ Ele evoca por si só ideias e pensamentos que transpassam o mero processo de musealização. A relação entre os valores agregados ao objeto pode se amplificar no seu processo de digitalização ou virtualização, o que reforça, em certa medida, o pensamento elaborado por Malraux sobre a metamorfose dos objetos a partir da sua digitalização para uso virtual.

Percebe-se que, com a popularização da internet a partir dos anos de 1990, a relação museu-ambiente web e a virtualidade dos objetos museais na sua comunicação com o público virtual têm sido temas de preocupação de algumas instituições museológicas e pesquisadores da área. Embora trate-se de um tema central nas discussões para se pensar os caminhos que os museus deveriam seguir neste século, vemos, com o advento da pandemia de covid-19, que muitas instituições museológicas não estavam adequadas aos processos de mudanças provocadas pelos avanços tecnológicos. As transformações causadas pela pandemia levantaram alguns debates sobre o lugar do museu no mundo digital, debates em que se destacou, inclusive, a necessidade de se pensar novos profissionais na área cuja função permeie o espaço virtual. Dessa forma, pretendemos sublinhar algumas mudanças ocasionadas pela pandemia na relação dos museus com o mundo virtual digital, revelando, em alguns casos, que muitas instituições museológicas não acompanharam os processos de transformações tecnológicas e, por isso, encontram dificuldades em transpassar para o ambiente virtual as mesmas funções realizadas no plano físico, principalmente quanto ao uso do objeto museológico digital e toda a dinâmica que envolve a sua musealização. 
37. Disponível em: <https:// bit.ly/3B0S3Rq>. Acesso em: 1 out. 2021.

fenômeno da virtualização e a consequente metamorfose do objeto museológico sofreram uma ascensão no período da pandemia e provocaram efeitos diretos sobre o campo museal. A Rede Europeia de Organizações de Museus (Nemo), em pesquisas recentes, aponta que mais de $60 \%$ dos museus europeus aumentaram sua presença on-line desde o início da pandemia. ${ }^{37} \mathrm{~A}$ maioria desses museus passaram a investir em passeios virtuais, exposições online, criação de podcasts, atividades educativas e digitalização dos seus acervos para acessos virtuais. ${ }^{38}$

Podemos destacar algumas importantes ações dos museus diante da pandemia, realizadas por meio dos acervos digitais, como o Museu Britânico, que disponibilizou em seu site mais da metade da sua coleção, com 4,5 milhões de objetos, além de mais 1,9 milhão de imagens, das quais cerca de 280 mil foram divulgadas pela primeira vez. ${ }^{39}$ Da mesma maneira, disponibilizou no Google Arts and Culture uma experiência de visitação em 3D à exposição do museu. ${ }^{40}$ Ainda na Inglaterra, é interessante trazer a experiência desenvolvida pelo museu Hastings Contemporary, localizado na cidade de Hastings, que desenvolveu passeios de robô, um dispositivo de "telepresença" móvel ativado por Wi-Fi que circula pela galeria e envia uma transmissão de vídeo aos públicos do museu que o acessam a partir de suas casas. ${ }^{41}$ A operação do robô se estabelece por meio de um navegador web que vincula a sua câmera aos computadores do público visitante virtual, que o controla com as setas do teclado. Isso permite que o visitante passeie por toda a galeria do museu e desenvolva uma experiência virtual com os acervos do museu.

Esses são apenas dois exemplos dos milhares de programas desenvolvidos pelos museus na Europa. ${ }^{42}$ Vemos, da mesma forma, os museus desenvolverem no continente americano atividades virtuais que se ampliaram devido ao distanciamento social ensejado pela pandemia. Interessante experiência virtual foi a desenvolvida pela National Gallery of Art na cidade de Washington, nos Estados Unidos da América, que viabiliza uma visita em 3D à galeria do museu permitindo uma interação muito próxima da experiência física, na medida em que o visitante virtual pode, por meio das ferramentas disponíveis no site, caminhar pelas salas, aproximar-se das obras e realizar leituras disponíveis sobre os acervos, além de medir o tamanho das obras para obter uma visão concreta da sua dimensão. ${ }^{43}$ No México, o Museu Frida Kahlo procurou estratégias para manter as atividades culturais durante a pandemia e anunciou, em abril de 2020, que abriria o museu para visitação de forma virtual e gratuita. ${ }^{44}$ A visita virtual permite ao público
38. Disponível em: <https:// bit.ly/3mlaiuT $>$. Acesso em: 1 out. 2021.

39. Disponível em: <https:// em: 1 out. 2021.

40. Disponível em: <https:// bit.ly/3omlryd $>$. Acesso em: 1 out. 2021.

41. Disponível em: <https:// nyti.ms/3ipd94Q>. Acesso em: 1 out. 2021.

42. Disponível em: <https:// bit.ly/2YjW2un>. Acesso em: 30 set. 2021.

43. Disponível em: <https:// bit.1y/3B45UX4>. Acesso em: 10 set. 2021.

44. Disponível em: <https:// bit.ly/3uDotPB $>$. Acesso em: 11 set. 2021. bit.ly/3zWhSRf $>$. Acesso 
45. Disponível em: <https:// bit.ly/3B21hgp>. Acesso em: 30 set. 2021 .

46. ICOM-Brasil (2020a, p.18-23)

47. Beiguelman (2020).

48. A maioria das ações dos museus brasileiros voltadas para o público virtual durante a pandemia, são articuladas em redes sociais como Facebook, Twitter, Instagram, YouTube etc. Assim, as críticas apresentadas por Giselle Beiguelman inserem-se nessa perspectiva em que a falta de investimento em tecnologias digitais e formação adequada leva os museus brasileiros a não conseguirem produzir, em seus próprios sites, ações que promovam uma experiência ao público virtual de interagir com os espaços das exposições e objetos museológicos estabelecendo uma relação aberta, dinâmica e dialética na qual o indivíduo se conheça e se reconheça por meio da comunicação do e com - o objeto.

49. Beiguelman, op. cit.

50. Disponível em: <https:// bit.ly/3Fc8VqQ>. Acesso em: 30 set. 2020 . observar os jardins e as salas da exposição onde há objetos pessoais e pinturas de Frida Kahlo, além das exposições temporárias. ${ }^{45}$ Assim, o espaço museal do Museu Frida Kahlo, digitalizado por meio da tecnologia 3D, oferece que o visitante entre em contato com os objetos musealizados, cujas interfaces digitais trazem uma relação virtual de experiência com a musealidade do objeto e do próprio espaço, por meio do aparato tecnológico virtual.

Similarmente, o Comitê Brasileiro do ICOM (ICOM Brasil) destaca o crescente número de ações virtuais promovidas pelos museus brasileiros desde o início da pandemia de covid-19, apresentando dados que destacam a interação do público online com os museus. ${ }^{46} \mathrm{Na}$ realidade brasileira, o uso "forçado" do ambiente virtual provocado pela pandemia revelou, em certo sentido, que os museus brasileiros não se prepararam de maneira adequada para a completa experiência que a imersão virtual pode proporcionar ao público. Giselle Beiguelman levanta essa discussão de maneira pontual. ${ }^{47}$ Segundo a autora, os museus, as galerias de artes e os centros culturais não se preocuparam em desenvolver conteúdos artísticos e culturais exclusivamente para a web e, consequentemente, tiveram que utilizar como únicos campos de comunicação online as redes sociais, o e-commerce e, sobretudo, o Google Arts and Culture. Para a autora, essas instituições culturais brasileiras não estavam preparadas para desenvolver esse conteúdo exclusivo para o ambiente web. ${ }^{48}$

Segundo a autora, foram desenvolvidas algumas poucas ações de integração do museu com o ambiente virtual, como é o caso do Museu do Ipiranga, que se integrou ao Galleries, Libraries, Archives, and Museums (Glam), da Wikipédia, visando à expansão do seu acervo em meio digital, contemplando imagens e verbetes críticos e de caracterização das obras do museu. ${ }^{49}$ Além disso, o museu tem aumentado o seu engajamento nas redes sociais, principalmente por meio do Instagram, tratando majoritariamente da importância da atuação digital dos museus. Outros museus procuraram se engajar propondo ações virtuais. $\bigcirc$ Museu do Amanhã retomou suas atividades com a sua exposição temporária "Pratodomundo - Comida para 10 bilhões", que esteve em cartaz em 2019 e que, diante da pandemia, teve a sua exposição realizada de forma virtual. ${ }^{50}$

As experiências de visita virtual são o ponto de ação dos principais museus tradicionais brasileiros, algumas das quais podem ser acessadas pelos próprios sites dos museus; outras, através da plataforma Google Arts and Culture. Parte desses museus, além de permitir a visita, possibilita a opção de realizá-la de maneira guiada, por meio de um audioguia, e insere algumas ferramentas de acessibilidade nos museus. O Museu da República explora de maneira significativa essa ferramenta de visita guiada em seu site, embora a navegabilidade seja em 
alguns pontos difícil para pessoas que não tenham afinidade com as ferramentas digitais. ${ }^{51} \bigcirc$ Museu Nacional realiza a visita virtual de forma guiada por meio do Google Arts and Culture. No tour, feito com a utilização da tecnologia street view, o usuário pode contemplar como era todo o acervo antes do incêndio no prédio. No passeio virtual, que leva cerca de dez minutos, o visitante é guiado pelos principais objetos do conjunto do museu, acompanhado por imagens interativas e áudios que descrevem cada peça. ${ }^{52}$

Houve também uma crescente produção de conteúdo digital nos principais museus brasileiros com o objetivo de fomentar a interação com o público. Ações diversificadas foram realizadas, reestruturando a maneira como os museus atualizam a sua missão a partir da perspectiva virtual. A linguagem das redes sociais tornouse ferramenta importante nesse processo. O Museu de Arte de São Paulo (Masp) convidou seus seguidores no Instagram não apenas a conhecerem as obras virtuais do museu, mas também a interagirem com ele. A ação de maior destaque é a campanha designada pela hashtag \#maspdesenhoemcasa. Às terças-feiras, o museu desafia o público a fazer releituras de uma obra do acervo. Como premiação, o museu oferece ao ganhador um passaporte para visitar gratuitamente o museu durante o período de um ano. Além dessa atividade, é realizado em todas as quartas-feiras um encontro virtual do projeto "Diálogos no acervo", 53 momento em que o público virtual é apresentado às obras da coleção do museu e é convidado a investigar novas relações entre obras, visitantes e mediadores. Às quintas-feiras ocorrem lives com conversas entre curadores do museu e convidados. ${ }^{54}$

- Museu de Arte Moderna (MAM) de São Paulo também procurou estruturar suas ações virtuais por meio de hashtags, o que gerou uma intensa participação do público virtual. O MAM criou uma programação online por meio da hashtag \#MAMonline, ${ }^{55}$ para se manter ligada a seu público no período da quarentena. Foram realizados tours virtuais, lives, quizzes, cursos online nos canais digitais do museu e apresentação de conteúdos até então inéditos. ${ }^{56}$ Como resultado, houve um aumento significativo no número de acessos do público às plataformas virtuais do museu.

Os museus que se encontram no conhecido Circuito Liberdade, na cidade de Belo Horizonte, no estado de Minas Gerais, ampliaram da mesma maneira o número de ações no âmbito virtual com o objetivo de manter o contato com o seu público durante o período da pandemia. ${ }^{57} \mathrm{Nas}$ redes sociais das instituições que figuram no Circuito Liberdade, foram incrementadas as informações sobre as edificações, os acervos e curiosidades sobre as instituições. Com a hashtag \#CCBBemCasa, o Centro Cultural do Banco do Brasil de Belo Horizonte (CCBB$\mathrm{BH}$ ) preparou conteúdos exclusivos em sua programação para serem acessados de
51. Disponível em: <https:// bit.ly/3iqNetl>. Acesso em: 30 set. 2020 .

52. Disponível em: $<$ https:// bit.ly/3D2jw5V >. Acesso em: 30 set. 2020.

53. Conforme consta no site do Masp, "o programa Diálogos no Acervo substitui o antigo modelo de visitas guiadas, em que os visitantes são conduzidos por um percurso com o anseio de abranger a totalidade ou os destaques de uma exposição. Por meio de mediações semanais, o projeto visa instigar novas relações entre obras, visitantes e mediadores, repensando as formas possíveis de experiência na galeria. Evitando práticas educativas onde um fala e os outros apenas escutam e assentem, os encontros buscam promover diálogos múltiplos, com todos os tipos de público". Disponível em: $<$ https://bit.ly/2X9YAHl>. Acesso em: 5 jan. 2021.

54. Disponível em: <https:// bit.ly/3nfM8QV>. Acesso em: 5 jan. 2021.

55. Disponível em: <https:// bit.ly/3s607MS>. Acesso em: 5 jan. 2021.

56. Todas essas atividades envolvem variadas ações e são destacadas por meio de hashtags, a saber: \#MAMTourVirtual, \#HistóriasDoAcervo, \#MAMquiz, \#ArtistaDaSemana, \#MAMEducativo, \#tbt, \#MAMParaOuvir, \#HistóriasDoMAM, \#DicaDeLeitura, \#LivenoAteliê e \#MAMCursosOnline.

57. O Circuito Liberdade é um projeto do governo do estado de Minas Gerais que reúne, em um mesmo local, espaços culturais diversos, a partir de parcerias com instituições públicas e privadas. É composto pelas instituições Biblioteca Pública Estadual de Minas Gerais, Palácio da Liberdade, Arquivo 
Público Mineiro, Museu Mineiro, Centro de Arte Popular Cemig, Cefart Liberdade, BDMG Cultural, Espaço Cultural da Escola de Design UEMG, Espaço do Conhecimento UFMG, MM Gerdau - Museu das Minas e do Metal, Memorial Minas Gerais Vale, Centro Cultural Banco do Brasil, Casa Fiat de Cultura, Academia Mineira de Letras e Centro Cultural Minas Tênis Clube.

58. Disponível em: <https:// bit.ly/3hLnjeo $>$. Acesso em: 5 maio 2021.

59. Disponível em: <https:// bit.ly/2JLioxw>. Acesso em 5 jan. 2021.

60. Disponível em: <https:// bit.ly/3rXpnVd>. Acesso em: 5 jan. 2021.

61. Disponível em: <https:// bit.1y/3nl6mbU>. Acesso em: 5 jan. 2021.

62. Disponível em: <https:// bit.ly/38ehB1q>. Acesso em: 5 jan. 2021.

63. O termo "instagramado" aqui se refere ao fato de o perfil do Instagram do MON ter recebido muitos acessos e vasta interação. Isso se difere do termo "instagramável”, fenômeno relacionado à utilização dos espaços com o único objetivo de fotografar, postar no Instagram e receber um número grande de curtidas. Dentro desse novo fenômeno, os museus tornaram-se um espaço de destaque, pois algumas start-ups criaram museus cujo único objetivo é fazer com que o público visitante interaja com cenários mega coloridos e interativos, registre cada momento e poste no Instagram. Disponível em: <https://bit.ly/3F7Xf8x>. Acesso em: 5 jan. 2021.

64. MON (2020) maneira virtual. Exposições, shows, peças teatrais e mostras cinematográficas e de arte-educação foram disponíveis de forma gratuita. Dentre as ações, constam a visita virtual ao CCBB-BH pelo Google Arts and Culture; a realização de um webinar com Pieter Tjabbes, curador da exposição "Egito Antigo - do cotidiano à eternidade"; e visitas à exposição "Ivan Serpa - A expressão do concreto". ${ }^{58}$ Além disso, por meio da hashtag \#InesquecíveisDoCCBBBH são apresentadas no Instagram do CCBB-BH as grandes exposições que fizeram parte do seu catálogo. ${ }^{59}$ Outra hashtag de destaque é a \#CCBBeducativoEmCasa, vinculada à apresentação de vídeos de visitas mediadas às exposições do museu. ${ }^{60}$ Por sua vez, o Memorial Minas Vale deu destaque, em seu site, para a visita virtual e uma programação semanal de atividades online. Os acervos de vídeos, com shows e oficinas, estão disponíveis no site do Memorial. Além disso, o Memorial Minas Vale tem realizado uma série de produção e exibido vídeos com artistas, para apoiar a classe artística e manter o contato ativo com o público virtual. ${ }^{\circ 1}$ A Casa Fiat de Cultura criou uma campanha com a hashtag \#CasaFiatdeCulturaComVocê, para divulgar uma série de vídeos inéditos que relembram suas principais exposições internacionais e mostras temáticas, além de apresentar o Programa Educativo nas redes sociais. ${ }^{62}$

No estado do Paraná, em Curitiba, o Museu Oscar Niemeyer (MON) intensificou suas ações produzindo conteúdo para o público virtual. Isso gerou um aumento de interação dos usuários com as redes sociais do museu, tornando-o um dos museus mais "instagramados" do Brasil. ${ }^{63}$ Figurando em quarto lugar, o MON chegou a alcançar mais de 47 mil publicações ${ }^{64}$ e parte desse aumento se deve às atividades online vinculadas à hashtag \#monemcasa. Suas atividades de mediações e oficinas artísticas alcançaram mais de 1 milhão de usuários virtuais. As ações se dividem entre exposições online por meio do Google Arts and Culture, oficinas artísticas, oficinas em vídeos apresentadas por artistas com obras do acervo do museu e oficina de artes para pessoas acima de 60 anos. ${ }^{65} \mathrm{Em}$ Santa Catarina, na cidade de Florianópolis, o Museu de Arte de Santa Catarina (Masc), por meio do Núcleo de Ação Educativa (NAE), desenvolveu o projeto "MASC Família em Casa", com o objetivo de apresentar conteúdos relacionados a obras e artistas da coleção do museu e a assuntos que envolvem a história e a memória do Museu. ${ }^{66}$ Por meio da hashtag \#MASCFAMílLASEMCASA, o museu passou a divulgar os conteúdos todas as sextas-feiras em suas páginas no Facebook e Instagram. Em Porto Alegre, no Rio Grande do Sul, o Museu de Porto Alegre desenvolveu no seu Instagram um programa de lives chamado "Lives do Museu", para tratar de diversos temas relacionados à história de Porto Alegre. ${ }^{67}$

As visitas virtuais e as redes sociais como alternativas ao distanciamento social causado pela pandemia são também fortemente utilizadas pelos principais 
museus da região Nordeste do Brasil. Em Salvador, o Museu de Arte Moderna da Bahia (MAM-BA) disponibilizou uma visita virtual a todo o espaço do museu. ${ }^{68}$ Vendo as redes sociais como principal ferramenta de comunicação com o seu público virtual, trouxe para sua rede o consolidado projeto Jam no Mam e lançou a hashtag \#jamnomam. ${ }^{69}$ Tendo a música como uma das suas principais atividades, - MAM-BA tem lançado na pandemia uma série de lives dentro do projeto "Papo de Músico", com apresentações de diversos músicos da região. ${ }^{70}$ Em Sergipe, no Museu da Gente Sergipana, na cidade de Aracaju, foi inaugurada em agosto de 2019 uma visita virtual com o objetivo de manter o público próximo desse espaço. Com esse lançamento, ainda em 2019, o site virtual do museu já havia recebido mais de 280 mil acessos. ${ }^{71}$ No mesmo museu, celebra-se todos os anos, nos meses de agosto a outubro, o Dia do Folclore e o Dia da Sergipanidade. Diante do isolamento social, o museu criou a campanha "Sergipanize-SE" para divulgar e valorizar a identidade cultural local. Toda a ação de imersão nesse universo ocorreu de forma virtual por meio de plataformas digitais, com a finalidade de propor uma interação entre o público virtual e os grupos participantes da celebração. Para isso, o museu lançou em seu Instagram uma coleção de filtros com molduras artísticas e trajes virtuais com foco nas manifestações culturais do Largo da Gente Sergipana. ${ }^{72}$ Além dessas iniciativas, o museu, associado ao Instituto Banese e ao Governo de Sergipe, lançou em maio de 2020 o edital "Quarentena da Gente", com o objetivo de premiar projetos culturais de artistas sergipanos ou residentes no estado, mantendo, assim, a criação e produção cultural local. Os projetos premiados foram apresentados em lives no Instagram do Museu da Gente Sergipana. ${ }^{73}$ No Museu do Homem do Nordeste, em Recife, a principal ação de interação com o público virtual, estabelecida por meio da ação virtual com a hashtag \#MuniciosPE, é a série chamada "História dos Municípios de Pernambuco", que busca contar breves histórias dos municípios pernambucanos.

As ações no âmbito virtual em meio à pandemia parecem diminuir quando visualizamos alguns museus nas regiões Norte e Centro-Oeste do Brasil. Um dos museus mais visitados em Macapá, o Museu Sacaca, não apresenta nenhuma ação, em suas redes sociais e em seu site, voltadas para o público virtual durante a quarentena. ${ }^{74}$ No estado do Amazonas, as únicas iniciativas são encontradas no site da Secretaria de Cultura e Economia Criativa, com destaque para o projeto "Cultura sem sair de Casa". ${ }^{75} \bigcirc$ projeto abrange a apresentação de alguns museus do estado, assim como visitas guiadas nesses mesmos museus. Destaca-se o projeto \#ficanaredemaninho, que tem como objetivo reunir vídeos de atividades culturais dos artistas do Amazonas. ${ }^{76}$ No Pará, no Museu Paraense Emílio Goeldi, uma das mais importantes instituições museológicas do Brasil, as ações virtuais se
65. Disponível em: <https:// bit.ly/3rXhwas $>$. Acesso em: 5 jan. 2021.

66. Masc... (2020).

67. Disponível em: $<$ https:// bit.ly/3pW08AS >. Acesso em: 5 jan. 2021.

68. Disponível em: <https:// bit.ly/3ocHLY5>. Acesso em: 5 jan. 2021.

69. Para saber mais sobre o projeto, acesse o site do Jam no Mam. Disponível em: <https://bit.ly/3onC6RZ> Acesso em: 21 abr. 2021.

70. Disponível em: <https:// bit.ly/395C6wy>. Acesso em: 5 jan. 2021.

71. Mais de 280 mil... (2020).

72. Disponível em: <https:// bit.ly/3okgq6h>. Acesso em: 6 maio 2021 .

73. Disponível em: <https:// bit.ly/397vyxo >. Acesso em: 6 jan. 2021.

74. Disponível em: <https:// bit.ly/3odr4f $4>$. Acesso em: 6 jan. 2021.

75. Disponível em: <https:// bit.ly/35fl65Q>. Acesso em: 6 jan. 2021.

76. Disponível em: <https:// bit.ly/3hK8VTL>. Acesso em: 6 jan. 2021. 
77. Disponível em: <https:// bit.ly/3rXh0JC $>$. Acesso em: 6 jan. 2021.

78. Disponível em: <https:// bit.ly/35dvzyP $>$. Acesso em: 6 jan. 2021

79. Disponível em: <https:// bit.ly/38idD89>. Acesso em: 6 jan. 2021.

80. Disponível em: <https:// bit.ly/3rUhT5v>. Acesso em: 6 jan. 2021.

81. Unesco (2020) estabeleceram apenas em nível de caráter científico, talvez pelo próprio perfil de instituição de pesquisa que o museu possui. ${ }^{77} \mathrm{Na}$ região Centro-Oeste visualizamos os mesmos problemas. Na cidade de Goiás, o Museu Casa de Cora Coralina viu-se em uma situação crítica financeiramente devido à falta de visitas. ${ }^{78} \mathrm{O}$ reflexo disso é a ausência de ações no âmbito virtual nas redes sociais. ${ }^{79}$ Em Brasília, por ser a capital federal, essas ações virtuais foram desenvolvidas em maior escala. $O$ Museu Nacional da República lançou uma série de atividades através do Instagram como forma de interação com o público. As principais estabeleceram-se por meio das hashtags \#meuMUSEU, com a qual o museu convidava os visitantes a compartilharem fotos de suas visitas na instituição; \#MUSEUemcasa, vinculada à apresentação de uma série de vídeos de artistas que expuseram no museu, explicando suas obras; a hashtag \#FiltromeuMUSEU, que refere-se aos filtros do prédio do museu com os quais os usuário podem simular esse espaço em suas fotos; e a hashtag \#MUSEUcomMusica, que divulga músicas de diversos artistas veiculadas no aplicativo de Spotify. ${ }^{80}$

Essa realidade das regiões Centro-Oeste e Norte do Brasil reflete em certa medida a projeção levantada pela Unesco de que 13\% dos museus menores estariam seriamente ameaçados de não conseguirem retomar as atividades no pós-pandemia devido à falta de verba ${ }^{81}$ Sabemos que a própria falta de recursos reflete diretamente na escolha de sites mais bem elaborados, tanto no que se refere ao design quanto a sua navegabilidade. Mais do que isso, os recursos humanos e financeiros de uma instituição influenciam na contratação de pessoal especializado para tratar exclusivamente dessas ações em âmbito virtual. Uma visita rápida aos museus aqui apresentados demonstra que quanto mais apoio financeiro o museu recebe, mais profundamente elaboradas são as ações com o público virtual no período de pandemia.

\section{A VIRTUALIZAÇÃO COMO EXPERIÊNCIA DO REAL: O PROBLEMA DAS TECNOLOGIAS NOS MUSEUS BRASILEIROS PARA UMA EXPERIÊNCIA MUSEAL VIRTUAL}

Retomando o fenômeno da virtualidade discutido neste artigo, essas experiências, tanto nos sites e redes sociais dos museus quanto por meio de ferramentas como Google Street View, suscitam a reflexão sobre em que medida esses ambientes virtuais dos museus permitem uma experiência museológica virtual, assim como sobre a construção de experiências e narrativas no espaço físico. Sobre esse ponto, a crítica de arte, jornalista e curadora Nathalia Lavigne faz importantes 
reflexões em seu artigo publicado na Folha de S.Paulo, buscando analisar o excesso de lives e museus virtuais que passaram a ocorrer a partir da pandemia. ${ }^{82}$ Ao analisar as plataformas virtuais de navegação em museus, com destaque para - Google Street View, a autora traz uma interessante questão que converge com o problema discutido neste artigo em relação à experiência virtual e a sua relação com o público virtual. Para a autora, essas plataformas virtuais que buscam simular a experiência que se tem no espaço físico desconsideram alguns fenômenos que envolvem a experiência no espaço museal, no que diz respeito à relação entre visualidade e corpo, que se estimula pela relação com o espaço.

Segundo a autora, a visita a um museu envolve uma série de experiências coreográficas corporais que determinam de maneira significativa como nos relacionamos com os objetos musealizados. Embora plataformas como o Google Arts and Culture e redes sociais como o Instagram ofereçam ampla possibilidade de navegação e interação com os museus, as experiências virtuais podem provocar um certo desconforto se elas não forem pensadas a partir dos usos desses objetos musealizados no âmbito virtual. Esse tema é o ponto central discutido nesse artigo e parece figurar como um dos focos de discussões no período da pandemia, que deverão ser levados em consideração pelos museus no pós-pandemia.

O destaque da crítica de Giselle Beiguelman refere-se ao fato de que os museus precisam repensar a sua presença no ambiente virtual, a fim de focarem não somente nas redes sociais, mas também pensarem e planejarem suas ações levando em consideração o ambiente web. Quanto a esse aspecto, é necessário cogitar o uso de profissionais especializados na área, como designers, artistas e programadores. Tal reflexão já tem sido levantada pela Museum Sector Alliance (Mu. SA), ao identificar quatro novos perfis profissionais para o setor de museus a partir das observações e demandas que surgiram em decorrência pandemia e do crescente uso do meio virtual como ferramenta de comunicação do museu com seu público; os perfis profissionais são: Gestor de Estratégia Digital, Curador de Coleções Digitais, Desenvolvedor de Experiência Digital Interativa e Gestor de Comunidade Online.83

Certamente, um dos principais desafios no pós-pandemia serão os enfrentados pela maioria dos museus com menor renda, que mesmo antes da pandemia já encontravam barreiras para o desenvolvimento de suas atividades museológicas. A questão que se coloca neste artigo, no entanto, envolve outro aspecto teórico referente à função prática dos museus e à maneira como essas experiências podem ser transferidas para o ambiente virtual.

O Museu é um fenômeno identificável por meio de uma relação muito especial entre Homem, Espaço, Tempo e Memória, sendo esta percebida como musealidade dentro de uma perspectiva museológica. ${ }^{84} \mathrm{~A}$ musealidade, como
82. Lavigne (2020).

83. Disponível em: <https:// bit.ly/3uwmBIe>. Acesso em: 30 set. 2021.

84. Expressamos Museu, com "m" maiúsculo, quando a intenção é representá-lo dentro da percepção destacada por Scheiner enquanto “'museu como fenômeno', nas suas diferentes interfaces com o Real" (SCHEINER, 2012, p. 17). Fenômeno que se "remete à idéia do museu-em-si, uma espécie de museu-idéia, ou museu-potência(érgon). Conceber o museu como fenômeno equivale a pensá-lo como pura museidade, ou como uma absoluta abstração e, por isso, destituído de substância histórica” (BORGES, 2011, p. 6). 
85. Cf. Cândido, Aidar e Martins (2015).

86. Falk e Dierking apud Köptcke (2003).

87. Cf. Roque (2010, p. 49).

88. Cury, op. cit.

89. Cf. Braga (2003) vimos, se estabelece como a potência ou a qualidade identificada em certas representações do real, o que as torna relevantes na ótica dos museus. A própria percepção dessa musealidade é um produto de sistemas e valores específicos de cada cultura e, da mesma forma, das instituições museológicas. Nessa lógica, a experiência museal dos públicos nos museus está intimamente ligada à forma como os museus estabelecem suas dinâmicas de comunicação. ${ }^{85}$

A experiência museal, conforme destacam Falk e Dierking, se estabelece por meio da complexa relação estabelecida entre o visitante do museu e o espaço museológico, momento em que os processos de construção de sentido e de reflexão se dão por meio da articulação entre aquele e o espaço expográfico. ${ }^{86}$ O elemento estruturante dessa relação museológica se dá pela comunicação. Por isso, a comunicação é percebida como função primordial dos museus, de modo que $o$ ato de comunicar foca-se no objeto museal, com uma estratégia narrativa cujo discurso é assimilado na relação entre emissor e receptor. ${ }^{87}$ Para Marilia Xavier Cury, o sistema de comunicação museológico é o conjunto teórico que envolve todos setores do museu, com destaque a três sistemas fundamentais: as competências técnicas, políticas e administrativas. ${ }^{88}$ Nesse processo, a exposição seria o elemento central da comunicação: é onde ocorre a experiência sensorial que se estabelece por meio das cores, da iluminação, dos detalhes, textos, circuitos e, principalmente, dos objetos museais. ${ }^{89}$

O museu, enquanto um espaço comunicacional, apresenta o seu discurso museológico através da comunicação, em que os emissores, os próprios museus, elaboram a exposição por meio de códigos com o intuito de apresentar uma mensagem e o público receptor decodifica e complementa essa mensagem com as experiências no espaço expográfico. Nessa relação com o objeto, o contato com a linguagem museológica faz com que o sujeito estabeleça uma reflexão, em que sua própria percepção sobre o real se modifica a partir da experiência museal. Assim, o sujeito agrega ganhos significativos e contribui para a ampliação do campo de possibilidades da construção identitária, da percepção crítica da realidade cultural e do estímulo à produção do conhecimento. A discussão que se coloca a partir deste ponto é de que maneira essa experiência museológica pode ser concebida no âmbito virtual.

Os casos analisados das ações promovidas pelos museus brasileiros diante da impossibilidade de abrirem suas portas, que se referem a experiências unicamente virtuais, demonstraram em certa medida que essas experiências caracterizam-se muito mais como interativas do que reflexivas. $\bigcirc$ museu se diferencia por ações específicas no comunicar, o que tende a provocar no indivíduo uma reflexão a partir do contato com os objetos. Nesse sentido, as narrativas, as iluminações, os textos, influenciam 
na percepção do sujeito. Isso ainda não é reproduzido de maneira semelhante no ambiente virtual, porque este requer uma outra linguagem museológica. A maioria das ações dos museus no espaço virtual destacam-se mais como interativas, principalmente no ambiente "instagramável" e no uso das hashtags, cuja única função é entreter e atrair um número maior de seguidores, mas não reflete a experiência museológica dentro do museu em si. Isso reverbera nas ações educativas, nas visitas e em todas as ações virtuais dos museus. Portanto, o desafio dos museus brasileiros é proporcionar uma experiência museológica que busque trazer uma reflexão em que o indivíduo se transforme a partir da experiência virtual.

Ficou comprovado que os usos do ambiente virtual aumentaram a relação do público com os museus, o que se configura como um grande mérito no uso de plataformas digitais como forma de atrair a atenção dos usuários. Esse é um caminho viável para que sejam desenvolvidas ferramentas de maneira adequada e, consequentemente, para que os museus possam reproduzir no ambiente virtual as ações e discursos que realizam no plano real. Para atingir tal objetivo, parece necessário que seja estabelecida uma linguagem virtual que tenha a intenção de trazer essas experiências. Essa face virtual do museu deve se estruturar com uma linguagem que se constitua por meio da criação e informação. Conforme destaca Tereza Scheiner sobre os museus virtuais,

museu virtual/digital (o verdadeiro 'novo' museu) comprova que é possível representar (e interpretar) o mundo sem a presença do que se convencionou chamar 'objeto de museu': parcela da natureza ou coisa fabricada pelo homem. A imagem presentifica o lugar, o acontecimento - "como as antigas musas, traz à presença (do homem) aquilo que, sem ela, seria esquecimento" (SCHEINER, 1999a, p. 159). Ela também documenta: é um objeto integral, em sua virtualidade. Esse museu, que se institui na passagem do século XX para o $X X I$, é a mais legítima representação dos universos perceptuais do homem contemporâneo: desterritorializado (habita o universo digital), intemporal (existe apenas no presente), imaterial, fugaz, pode constituir-se pela presentificação imagética de um real externo ao homem ou das sensações do museu interior; e porque não tem modelo fixo, recria-se continuamente, segundo a vontade de seus criadores. Aqui, a 'relação específica' é com a linguagem imagética: "existir na imagem, ser ele mesmo um corpo virtual, estar num não tempo, num não lugar - eis o desejo absoluto do homem contemporâneo. Pois estar no mundo absurdo do simulacro representa a imortalidade" (SCHEINER, 1999a, p. 160). ${ }^{90}$

A partir da citação da autora, podemos observar que o Museu Virtual oferece importantes elementos para pensar ações museológicas no ambiente virtual. $\bigcirc$ museu virtual ou digital soma-se às formas de museus existentes. ${ }^{91} \bigcirc$ Museu, como símbolo comunicacional, tem suas interfaces entre o humano e o real estabelecidas por distintas dobras. Tereza Scheiner define-as como "Dobra do Real", pois o museu, 
92. Scheiner (2014).

93. European Heritage Alliance (2020). como instância narrativa de reflexão sobre o Real que nos é apresentado por meio das manifestações do Museu, faz uma abordagem do Real de maneira múltipla, no exercício cotidiano de identificar, analisar e interpretar. ${ }^{92}$ Da mesma forma, pode-se pensar em para estabelecer no ambiente virtual essas dobras como reflexo do Real, que contribua para uma experiência museológica manifesta no Museu.

Enquanto representação simbólica, a essência dos museus reside em sua capacidade de transformação. Independentemente do espaço físico, o Museu pode se revelar de formas definidas, como quando o espaço virtual constitui-se em um espelho e símbolo da sua "dobra real" e o leva a assumir diferentes formas, capturando, codificando e interpretando o patrimônio na virtualidade. É nesse universo virtual que se deve desenvolver uma linguagem museal específica de comunicação e conhecimento, de modo que o público virtual, imerso nessa experiência, possa estabelecer uma relação dialógica que o transforme a partir dos mecanismos museológicos que proporcionam uma experiência museal. Nesse procedimento, as linguagens devem ser pensadas para o seu uso na virtualidade. Os processos curatoriais devem se estabelecer enquanto dispositivos técnicos que irão determinar a formação, gestão e comunicação pública dos museus nos espaços virtuais com base nas evidências materiais do mundo real. Isso envolve pensar estratégias e contratar uma equipe qualificada que compreenda as diferentes linguagens, tanto museológicas quanto a linguagem Web - bem como suas ramificações que envolvem linguagem de programação, design, audiovisual, texto etc.

Sabemos que as tecnologias digitais não podem substituir totalmente a experiência direta de visitar um museu e a interação social que a acompanha, mas ela pode oferecer outras experiências que se assemelhem aos objetivos dos museus no âmbito físico. Essa preocupação tem levantado debates, como o destacado anteriormente desenvolvido pela Mu.SA. Outras instituições têm debatido os usos das tecnologias digitais pelos museus que aplicaram práticas bem-sucedidas para a criação de conteúdo tornando as coleções acessíveis online e aumentando a atratividade geral dos museus. A covid-19, com a obrigatoriedade do distanciamento social, gerou uma reflexão em torno do patrimônio cultural digital, ao estimular a criatividade dos museus nos seus engajamentos no âmbito virtual. $O$ tema foi abordado pelos membros do European Heritage Alliance, que em maio de 2020 lançaram o manifesto Cultural heritage: a powerful catalyst for the future of Europe, com destaque para o tema Digitally Transforming Europe, em que se indicou o papel de liderança europeu em relação ao patrimônio cultural digital e a potencialidade de se ampliar as ações dos museus no ambiente virtual com os usos de novas tecnologias, inteligência artificial e aprendizagem automática, de forma ética e humana. ${ }^{93}$ Um dos museus apresentados, o Riga Motor Museum, na 
Letônia, utiliza várias tecnologias digitais que possibilitam aos visitantes explorar as coleções em profundidade, ainda que virtualmente, por meio de guias de áudio, experiência de realidade aumentada, show de mapeamento de vídeo, estações de trabalho, projeções visuais, soluções multimídia, áudio experiência, exposições práticas e jogos. Esse conjunto de multimídia conduziu a resultados positivos, evidenciados pelo aumento do número de visitantes e reconhecimento internacional. ${ }^{94}$ Outro projeto de destaque é o Museu de Realidade Virtual Tholos, que combina ferramentas digitais inovadoras para hospedar coleções digitais e testemunhos de alto valor cultural acessíveis ao público. O Tholos funciona como uma espécie de "Teatro de Realidade Virtual" em forma de cúpula do Cosmos Helênico, com capacidade para 130 pessoas. É um edifício de excepcional projeto arquitetônico com infraestrutura tecnológica única, que abriga o acervo digital da Fundação do Mundo Helênico. Os shows são interativos, controlados pelo espectador e não estáticos. É uma experiência de imersão no mundo virtual, que se caracteriza pela resposta imediata, flexibilidade, originalidade e vivacidade. Seus programas são apresentados por um museum educator, com que os visitantes podem interagir através dos botões que se encontram em cada cadeira, e são parametrizados pelo museum educator para se adequarem ao público-alvo. ${ }^{95}$

Assim, as tecnologias digitais demonstraram seu valor no período de pandemia global, aproximando as pessoas, incentivando a criatividade e oferecendo um espaço virtual para construir ideias coletivamente. Contudo, ao contrário dos exemplos europeus, no Brasil vivemos em uma realidade bem distinta, pois apenas os grandes museus conseguiram utilizar as tecnologias digitais para criar ações em espaços virtuais de interação com o público. Essas experiências ainda perpassam os limites dos sites de visitas virtuais e das ferramentas das redes sociais como Instagram, Facebook e YouTube. Por exemplo, não se consegue alcançar uma experiência museológica no Instagram para além de lives, stories, compartilhamentos de fotos, usos de filtros, curtidas e interações por meio de comentários textuais. Essas plataformas permitiram aos museus alcançarem um público maior, mas persiste o grande desafio de transformar esse alcance virtual em ações museológicas virtuais desenvolvidas de acordo com a missão de cada museu. Em relação aos museus menores, ainda são maiores os desafios. Desprovidos de financiamentos, são restringidos a uma experiência limitada no ambiente web, com sites que ainda se assemelham aos dos anos 1990, de conteúdo mais informativo do que interativo, que pouco atrai a visitação do público virtual. Da mesma forma, isso é refletido nas redes sociais desses museus, que, sem uma equipe qualificada, tornam-se apenas espaços de repositórios de fotos e informações, sem qualquer interação ou engajamento com o público.
94. Innovation... ([2017]).

95. Disponível em: <https:// bit.ly/3rYlfVd>. Acesso em: 7 jan. 2021 
96. ICOM-Brasil (2020b).

97. Brulon (2020, p. 1).

\section{CONCLUSÃO}

Observamos que a experiência virtual pode servir como uma grande ferramenta de ações dos museus. $\bigcirc$ virtual surge como outra possibilidade de transformação dos indivíduos a partir da sua relação com os objetos museológicos. Ele colabora para a ampliação da sua função social já que serve como "plataforma para as aspirações e as necessidades de suas comunidades e de seus territórios", umas das principais ações destacadas pelo International Council of Museums Brasil (lcom-Brasil) em carta aberta para a comunidade museal brasileira. ${ }^{96} \mathrm{~A}$ pandemia mostrou que alguns museus ainda não estão preparados para proporcionar uma experiência virtual completa, na medida em que essas instituições não viram o meio virtual como foco de suas ações. Assim, os desafios para pensar as novas funções e características dos museus perpassam os usos virtuais e sua contribuição na missão dos museus.

Um dos grandes desafios dos museus no século XXI será repensar os usos das virtualidades no período pós-quarentena, e esse desafio se insere no próprio debate sobre pensar uma nova definição de Museu, que tem sido realizado pelo Icom-Brasil desde 2016 e tem gerado um amplo campo de discussão. Acreditamos que uma nova definição de museu deve repensar os hábitos digitais e os incorporar aos espaços museológicos. Que reconheça os museus nos espaços digitais não como uma promessa distante ou uma fonte de potencial inexplorado, mas sim um espaço virtual para construir ideias conjuntas. Para isso, é necessário aumentar os esforços digitais no futuro, após este período de extrema crise, com medidas de atividades digitais sem precedentes. Os orçamentos e estratégias devem responder a essas descobertas, aproveitar as vantagens dos esforços atuais e permitir investimentos em ofertas, serviços e infraestruturas.

A pandemia já provocou profundas transformações nas formas de agir dos museus, mas a atenção aos meios virtuais ainda requer novos métodos que devem ser considerados para o futuro. Por exemplo, para que os indivíduos tenham uma experiência completa, é preciso haver a democratização desse acesso. Isso envolve não somente o desenvolvimento de ações pensadas para o ambiente virtual, mas também como o público terá acesso a esse ambiente. Tal propósito se insere na própria discussão sobre decolonizar o pensamento museológico, como sugere Bruno Brulon ao nos convidar a propor um pensamento crítico "para repensar as práticas museais em regimes pós-coloniais". $97 \mathrm{Na}$ realidade brasileira, esse pensamento está associado à própria desigualdade social manifestada de maneira escancarada durante a pandemia. 
Para o lcom-Brasil, no futuro pós-pandemia, os museus terão um grande papel social e "esse futuro começa agora, e a solidariedade será imprescindível para a construção de um mundo mais igualitário, diverso e inclusivo". "98 Faz-se necessário pensar essa inclusão também no meio virtual e compreender que diversos grupos têm dificuldades em utilizar o ambiente virtual, por fatores como o conhecimento de idiomas e de usos das tecnologias. Deve-se considerar que cada indivíduo, de acordo com sua idade e condição social, tem uma percepção distinta do que the é apresentado. É essencial repensar esse novo conceito de público e o valor de culto atribuído à exposição no meio virtual, quanto à comunicação dos objetos dos museus e às affordances que exigem novos profissionais especializados. ${ }^{99}$

Como importante peça no campo cultural internacional, visto que muitos países, inclusive o Brasil, apoiam-se nas definições do lcom-Brasil para a construção de suas políticas públicas e institucionais, uma nova definição que leve em conta a importância dos museus no meio virtual pode ajudar na democratização do acesso às tecnologias, uma questão de direitos humanos básicos e de acesso à cidadania.
98. ICOM-Brasil, op. cit.

99. O conceito de affordances foi definido originalmente pelo psicólogo James Gibson em 1977, com o objetivo de denotar a qualidade de qualquer objeto que permite ao indivíduo identificar suas funcionalidades através de seus atributos (forma, tamanho ou peso) de maneira intuitiva e sem explicações. Refere-se a, por exemplo, perceber que uma cadeira oferece apoio e que, portanto, serve para se sentar, ou que uma maçaneta serve para abrir uma porta (GIBSON, 1977). Da mesma forma esse conceito pode ser pensado nas interfaces digitais dos museus, por meio do Design de Interação, quando o desenho dos elementos de uma aplicação virtual deve levar em consideração as affordances, de maneira que não se quebre o processo de percepção do usuário sobre a interação exploratória com os objetos virtuais, sem forçar o usuário a reaprender algo que ele poderia descobrir sozinho se estivesse em um ambiente físico do museu. 


\section{REFERÊNCIAS}

LIVROS, ARTIGOS E TESES

BENJAMIN, Walter. A obra de arte na era de sua reprodutibilidade técnica. In: BENJAMIN, Walter. Obras escolhidas. V. 1, Magia e técnica, arte e política. Trad. Sergio Paulo Rouanet. 3a. ed. São Paulo: Brasiliense, 1987a, p. 165-196.

BENJAMIN, Walter. Pequena história da fotografia. In: BENJAMIN, Walter. Obras escolhidas. V. 1, Magia e técnica, arte e política. Trad. Sergio Paulo Rouanet. 3a. ed. São Paulo: Brasiliense, 1987b, p. 91-107.

BORGES, Luis Carlos. Museu como espaço de interpretação e de disciplinarização de sentidos. Museologia e Patrimônio, Rio de Janeiro, v. 4, n. 1, p. 37-62, 2011.

BOWEN, Jonathan. Time for renovations: a survey of museum web sites. Archives $\mathcal{E}$ Museum Informatic, Pittsburgh, 1999. Disponível em: <https://bit.ly/3kB9geI>. Acesso em: 1 out. 2020.

BRAGA, Gabrielle Corrêa. Museus e público no Rio de Janeiro: mapeando serviços e qualidade. In: CONGRESSO BRASILEIRO DE SOCIOLOGIA, 11., 2003, Campinas. Anais [...]. Campinas: Unicamp, 2003. p. 1-22.

BRITANNICA, The Editors of Encyclopaedia. "World Wide Web". Encyclopedia Britannica, 27 Nov. 2019. Disponível em: <https://bit.ly/3uzI9Ur>. Acesso em 1 out. 2021.

BRULON, Bruno. Descolonizar o pensamento museológico: reintegrando a matéria para repensar os museus. Anais do Museu Paulista, São Paulo, v. 28, p. 1-30, 2020. Doi: <https://doi. org/10.1590/1982-02672020v28e1>.

CÂNDIDO, Manuelina Maria Duarte; AIDAR, Gabriela; MARTINS, Luciana Conrado. A experiência museal: discutindo a relação dos museus com seus visitantes na contemporaneidade. Museologia E Interdisciplinaridade, Brasília, DF, v. 4, n. 7, p. 308-315, 2015.

CHAGAS, Mário. Campo em metamorfose ou ainda bem que os museus são incompletos. In: BITTENCOURT, José Neves; BENCHETRIT, Sarah Fassa; TOSTES, Vera Lúcia Bottrel (eds.). História representada: o dilema dos museus. Rio de Janeiro: Museu Histórico Nacional, 2003. p. 239-250.

CURY, Marilia Xavier. Exposição: concepção, montagem e avaliação. São Paulo: Annablume, 2006.

DELOCHE, Bernard. Le musée virtuel: vers une éthique des nouvelles images. Paris: PUF, 2001. 
EUROPEAN HERITAGE ALLIANCE. Cultural heritage: a powerful catalyst for the future of Europe. [S. l.]: European Heritage Alliance, 2020. Disponível em: <https://bit.ly/3baRN8t $>$. Acesso em: 7 jan. 2021.

GIBSON, James Jerome. The theory of affordance. In: SHAW, Robert; BRANSFORD, John (eds.). Perceiving, acting, and knowing: toward an ecological psychology. New Jersey: Lawrence Erlbaum Associates, 1977. p. 67-82.

INTERNATIONAL COUNCIL OF MUSEUMS - BRASIL. O digital é real: experiências culturais dos públicos durante a pandemia. In: Dados para navegar em meio às incertezas: Parte II Resultados da pesquisa com públicos de museus. São Paulo: ICOM Brasil, 2020a. p.18-23. Disponível em: <https://bit.ly/39YSG1W>. Acesso em: 01 out. 2021.

INTERNATIONAL COUNCIL OF MUSEUMS - BRASIL. Carta aberta à comunidade museal brasileira: Dia Internacional dos Museus. [S. l.]: Icom, 2020. Disponível em: <https://bit. ly/3EWCgpk>. Acesso em: 22 set. 2020b.

KÖPTCKE, Luciana Sepúlveda. Observar a experiência museal: uma prática dialógica? Caderno do Museu da Vida, Rio de Janeiro, p. 5-21, 2003.

LÉVY, Pierre. O que é o virtual? São Paulo: Editora 34, 2011.

MALRAUX, André. Le musée imaginaire. Paris: Gallimard, 2006.

MAROEVIĆ, Ivo. Identity as a constituent part of museality. In: SYMPOSIUM MUSEOLOGY AND IDENTITY, 10., 1986, Buenos Aires. Anais [...]. Buenos Aires: Icom International Committee for Museology, 1986. p. 183-188.

PADILHA, Renata Cardozo. A representação do objeto museológico na época de sua reprodutibilidade digital. 2018. Tese (Doutorado em Ciência da Informação) - Universidade Federal de Santa Catarina, Florianópolis, 2018.

PATERNÒ, Fabio; MANCINI, Cristiano. Effective levels of adaptation to different types of users in interactive museum systems. Journal of the American Society for Information Science, Hoboken, v. 51, n. 1, p. 5-13, 2000.

REIS, Marina Gowert dos. Patrimônio cultural brasileiro na era digital: da digitalização de acervos à preservação participativa na internet. 2019. Tese (Doutorado em Memória Social e Patrimônio Cultural) - Universidade Federal de Pelotas, Pelotas, 2019.

ROQUE, Maria Isabel. Comunicação no museu. In: MAGALHÃES, Aline Montenegro; BEZERRA, Rafael Zamorano; BENCHETRIT, Sarah Fassa (orgs.). Museus e comunicação: exposição como objeto de estudo. Rio de Janeiro: Museu Histórico Nacional, 2010. p. 46-68. 
SCHEIDEL, Walter. The great leveler: violence and the history of inequality from the Stone Age to the Twenty-First Century. Princeton: Princeton University Press, 2017.

SCHEINER, Tereza Cristina. Conceitos, termos e linguagens da museologia: novas abordagens. In: ENCONTRO NACIONAL DE PESQUISA EM CIÊNCIA DA INFORMAÇÃO, 15., 2014, Belo Horizonte. Anais [...]. Belo Horizonte: UFMG, 2014. p. 4644-4663.

SCHEINER, Tereza Cristina Moletta. Imagens do não-lugar: comunicação e o patrimônio do futuro. Tese (Doutorado em Comunicação Social) - Universidade Federal do Rio de Janeiro, Rio de Janeiro, 2004.

SCHEINER, Tereza Cristina Moletta. Museu, museologia e a "relação específica": considerações sobre os fundamentos teóricos do campo museal. Ciência da Informação, Brasília, Df, v. 42, n. 3, p. 358-378, 2013.

SCHEINER, Tereza Cristina Moletta. Repensando o museu integral: do conceito às práticas. Boletim do Museu Paraense Emílio Goeldi: Ciências Humanas, Belém, v. 7, n. 1, p. 15-30, 2012.

WALSH, Peter. The neon paintbrush: seeing, technology, and the museum as metaphor. Journal of the American Society for Information Science, Hoboken, v. 51, n. 1, p. 39-48, 2000.

SITES

BEIGUELMAN, Giselle. Atropelados pela pandemia, museus rastejam na internet. Folha de $S$. Paulo, São Paulo, 17 abr. 2020. Disponível em: <https://bit.ly/3kzyf1V>. Acesso em: $1^{\circ}$ out. 2020.

INNOVATION and digitalization of cultural resources in Riga Motor Museum in Latvia. Interreg Europe, Lille, França, [2017]. Disponível em: <https://bit.ly/3bfjOeY>. Acesso em: 7 jan. 2021.

LAVIGNE, Nathalia. Overdose de lives e museus virtuais causam cansaço e vertigem. Folha de $S$. Paulo, São Paulo, 17 abr. 2020. Disponível em: <https://bit.ly/39ycJEu>. Acesso em: 1 out. 2020.

MAIS DE 280 MIL pessoas já realizaram visita virtual ao Museu da Gente Sergipana. Museu da Gente Sergipana, Aracaju, 2020. Disponível em: <https://bit.ly/35ci4zf>. Acesso em: 6 maio 2021.

MASC - Famílias em casa. Fundação Catarinense de Cultura, Florianópolis, 27 maio 2020. Disponível em: <https://bit.ly/3hPDvLM>. Acesso em: 5 jan. 2021.

MON é um dos cinco museus mais "instagramados" do Brasil. Museu Oscar Niemeyer, Curitiba, 29 dez. 2020. Disponível em: <https://bit.ly/38ehZwY>. Acesso em: 5 jan. 2021. 
UNESCO: pandemia pode levar a fechamento de $13 \%$ dos museus do mundo. ONU News, [S. l.], 19 maio 2020. Disponível em: <https://bit.ly/3nf4m4V>. Acesso em: 5 jan. 2021.

VICK, Mariana. Pandemia: origens e impactos, da peste bubônica à covid-19. Nexo Jornal, São Paulo, 21 jun. 2020. Disponível em: <https://bit.ly/3ilgIWO>. Acesso em: $1^{\circ}$ set. 2020.

Artigo apresentado em: 06/01/2021. Aprovado em: 21/05/2021.

\section{(cc) BY}

All the contents of this journal, except where otherwise noted, is licensed under a Creative Commons Attribution License 